\title{
Hematological Alterations in Cisplatin Induced Toxicity in Rats and Its Amelioration by Andrographis paniculata
}

\author{
T. Rajendrakumar ${ }^{1 *}$, Suguna Rao ${ }^{1}$, M. L. Satyanarayana ${ }^{1}$, \\ H. D. Narayanaswamy ${ }^{1}$, S. M. Byregowda ${ }^{2}$ and N. B. Shridhar ${ }^{3}$ \\ ${ }^{I}$ Department of Veterinary Pathology, Veterinary College, KVAFSU, Hebbal, \\ Bangalore-560024, India \\ ${ }^{2}$ Institute of Animal Health and Veterinary Biologicals, KVAFSU, Bangalore, India \\ ${ }^{3}$ Department of Veterinary Pharmacology, Veterinary College, Vinobanagar, \\ Shimogga-577204, India \\ *Corresponding author
}

\section{A B S T R A C T}

\section{Keywords}

Andrographis paniculata, Wistar Albino rats, Hematological parameters

Article Info

Accepted:

07 March 2020

Available Online:

10 April 2020
Cisplatin $(\mathrm{CP})$ is considered one of the most effective and widely used anti-neoplastic drug in the treatment of different solid organ tumors. The present study was carried out to assess the hematological changes following $\mathrm{CP}$ administration in Wistar albino rats and its amelioration by extract of Andrographis paniculata (AP). The study included 60 Wistar albino rats were divided into 12 rats in each group. Group I served as normal control group. To group II rats, CP was administered at $7.5 \mathrm{mg} / \mathrm{kg}$ body weight intraperitoneally for single dose. Rats in group III were administered AP at the dose of $500 \mathrm{mg} / \mathrm{kg}$ body weight for 45 days. Group IV rats were pre-treated with AP 15 days prior to CP administration and followed by AP treatment for 45 days. Rats in group $\mathrm{V}$ were administered with $\mathrm{CP}$ and concurrently treated with AP extract at $500 \mathrm{mg} / \mathrm{kg}$ by oral gavaging for 45 days. The CP treated rats showed significant decrease in haemoglobin, TEC, TLC and platelet count as compared to normal control animals. Supplementation of AP to CP treated rats significantly improved the hematological parameters. The study concluded that damage to the hemopoietic system evident by deranged hematological parameters can be prevented by administration of extract of Andrographis paniculata.

\section{Introduction}

Cisplatin (CP) is a chemotherapeutic agent widely used in the treatment of several types of cancer including leukemia, lymphoma, sarcoma, cancer of lung, mammary gland and ovary (Hemati et al., 2012). Cisplatin is one of alkylating agents that directly damage
DNA resulting in cell apoptosis. Like most of chemotherapeutic drugs; cisplatin does not distinguish between cancer and normal cells and eliminates not only the fast-growing cancer cells but also other fast-growing cells in the body (Abdel et al., 2012). The oxidative stress through formation of the free radicals is also one of the mechanisms of 
cisplatin induced toxicity. Treatment with cisplatin frequently causes nephrotoxicity, hepatotoxicity, thrombocytopenia and bone marrow toxicity (Shalaby et al., 2014). To ameliorate the toxic effects of $\mathrm{CP}$ without inhibiting its anti-tumor effects, different experimental studies were carried out using combination of $\mathrm{CP}$ with radicular scavengers, antioxidants and natural foods with antioxidant properties (Iseri et al., 2007).

Andrographis paniculata (AP) is an important drug of Indian Systems of Medicine (ISM) and used in medicines. The AP identified as Hemedu Bumi and generally known as King of Bitter and cultivated in the tropical areas of India, China and South East Asia (Trivedi and Rawal, 2001). Andrographis paniculata was reported to possess antimicrobial, antiviral, antimalarial hepatoprotective, antioxidant, antidiabetic, antihyperglycemic, anti-diarrheal and anti-inflammatory and immunomodulatory effects (Akbar, 2011). Phytochemical analysis has revealed that it is a rich source of diterpenoids and 2 oxygenated flavonoids including andrographolide, neoandrographalide, isoandrographalide, andrographan- andrographosterin and stigmasterol (Bardi et al., 2014). Considering the above beneficial properties of AP, the present study was undertaken to evaluate the efficacy of Andrographis paniculata in ameliorating the toxic effects cisplatin on the hematopoietic system in Wistar albino rats.

\section{Materials and Methods}

Drugs and chemicals: Cisplatin (Kemoplat) was procured from Fresenius Kabi India Pvt. Ltd. Pune, India. and the ethanolic extract of Andrographis paniculata was obtained from Himalaya Herbal Pvt Ltd. Bangalore, India

Animals: Normal adult Wistar albino rats weighing approximately 180-200 grams were procured from commercial animal facility, Bangalore for the study. They were maintained under standard laboratory conditions and fed with ad libitum standard commercial rat feed and clean drinking water. The duration of experiment was for a period of 45 days and a prior permission was obtained from the Institutional Animal Ethics Committee (IAEC) for the conduct of the experiment.

Experimental design: The rats were maintained under standard laboratory conditions for a period of 15 days for acclimatization in the experimental animal house. The rats were divided, based on the body weight, into five groups with twelve rats in each group.

Group I: Normal control-injected with $0.5 \mathrm{ml}$ sterile PBS intraperitoneally on Day 1 and gavaged with PBS daily.

Group II: Positive control- toxicity induced with administration of cisplatin at $7.5 \mathrm{mg} / \mathrm{kg}$ body weight intraperitoneally for single dose.

Group III: Supplemented with ethanolic extract of Andrographis paniculata alone at the dose rate of $500 \mathrm{mg} / \mathrm{kg}$ body weight.

Group IV: Supplemented with Andrographis paniculata extract at the dose rate of $500 \mathrm{mg} / \mathrm{kg}$ bodyweight 15 days prior to induction of toxicity by $\mathrm{CP}$.

Group V: Supplemented with Andrographis paniculata extract at the dose rate of $500 \mathrm{mg} / \mathrm{kg}$ body weight concurrently with administration of $\mathrm{CP}$.

\section{Experimental induction of toxicity in rats}

To induce toxicity, the rats were fasted overnight and injected with cisplatin (CP) $7.5 \mathrm{mg} / \mathrm{kg}$ body weight by intraperitoneal 
routeas a single dose. The negative control animals were injected intraperitoneally with PBS alone. The rats in Group III were supplemented with extract of Andrographis paniculata at $500 \mathrm{mg} / \mathrm{kg}$ body weight alone for 45 days. The rats in Group IV were supplemented with extract of Andrographis paniculata at $500 \mathrm{mg} / \mathrm{kg}$ body weight, by oral gavaging, 15 days prior to and for 45 days following induction of toxicity with cisplatin (CP).The rats in Group V were supplemented with extract of Andrographis paniculata at $500 \mathrm{mg} / \mathrm{kg}$ body weight, intraperitoneally for 45days along with methotrexate at the rate of $7.5 \mathrm{mg} / \mathrm{kg}$ bodyweight by intraperitoneal route for single dose.

\section{Hematological parameters}

On the scheduled days of blood collection $\left(7^{\text {th }}, 14^{\text {th }}, 28^{\text {th }}\right.$ and $45^{\text {th }}$ day of the experiment $)$, few drops of blood was collected from the retro-orbital flexus, in a vial containing ethylene diamine tetra acetic acid (EDTA) as an anticoagulant for evaluation of hematological parameters such as total erythrocyte count (TEC), total leukocyte count (TLC), total platelet count and hemoglobin $(\mathrm{Hb})$. For the hematological evaluation, the auto hematology analyzer (BC-2800 VET, Mindray), was used.

\section{Results and Discussion}

The effect of $\mathrm{CP}$ administration on the hematological parameters was analyzed. The results indicated that $\mathrm{CP}$ caused a significant decrease $(P<0.05)$ in the levels of hemoglobin, TEC, TLC and total platelet count (Table 1, 2, 3, 4 and Figure 1, 2, 3, 4) in the Group-II when compared to normal control animals throughout the duration of the experiment. Similar observations in the blood parameters following cisplatin administration have also been reported by Ramya et al., (2013); Nasr (2014); Divya et al., (2016); Karale and
Kamath (2017); Shaymaa et al., (2017); Song et al., (2017); Bhachand raet al.(2018) and Lin et al., (2018). Cisplatin is one of the most potent cytotoxic agents, is reported to cause toxic side effects on different body organs such as hepatotoxicity, nephrotoxicity and bone marrow suppression.

Hematopoietic system is one of the most sensitive systems to evaluate the hazards effects of poisons and drugs in humans and animals (Lijuv et al., 2013). Chemotherapeutic drugs are usually cytotoxic which results in the killing cancer of cells although, unfortunately, the immune system is destroyed at the same time. Depending upon the proliferating nature, bone marrow cells are very sensitive to cytotoxic chemicals and easily susceptible to DNA damage especially undifferentiated population (Shaymaa et al., 2017). Inhibition of cell proliferation is one of the major causes of cisplatin induced myelotoxicity (Basu et al., 2015). The reduction in these values in the present study might be due the effect of cisplatin on bone marrow.

There was an etiological relationship between anemia and CP treatment. Such relationship could be explained through different mechanisms including destruction of bone marrow cells or increase osmotic fragility of RBCs. Thus, CP intoxication might lead to anemia as a result of either suppression the activity of hematopoietic tissues, impaired erythropoiesis, and accelerated RBCs destruction because of the altered RBCs membrane permeability (Hassan et al., 2010). Nowis et al., (2007) reported that cisplatin administration reduced erythropoietin, a haemopoietic growth factor, which further resulted in alteration of hematological parameters. Olas et al., (2005) showed that CP causes oxidative stress in human platelets and lymphocytes, which might reflect on their life expectancy, the induction of apoptosis, 
and thereby ultimately reduce the number of these cells in the blood. Markovic et al., (2011) suggested that, aside from reduction in the RBC number, decrease in platelets count might be due to $\mathrm{CP}$ inhibiting bone marrow activity or could be due to decreased production or increased consumption of platelets or due to the increased platelets aggregation. The previous results suggest that thrombocytopenia and leukopenia in cisplatin treated group were resulted from apoptotic effect of cisplatin on lymphocytes and platelets thereby ultimately reduced the number of these cells in the blood (Shymaa et al., 2017). In addition, bleeding due to intestinal affections by cisplatin and free radical induced red cell damage could be contributory for lesser erythrocyte count and hemoglobin values.

Table.1 The mean $( \pm \mathrm{SE})$ values of hemoglobin $(\mathrm{g} \%)$ of different groups at different time intervals

\begin{tabular}{|l|l|l|l|l|}
\hline \multirow{2}{*}{ Groups } & \multicolumn{4}{|c|}{ Days of post treatment } \\
\cline { 2 - 5 } & $07^{\text {th }}$ & $14^{\text {th }}$ & $28^{\text {th }}$ & $45^{\text {th }}$ \\
\hline GP-I & $13.4 \pm 0.258^{\mathrm{ax}}$ & $13.6 \pm 0.155 \mathrm{~d}^{\mathrm{ax}}$ & $14.4 \pm 0.15^{\mathrm{ay}}$ & $13.76 \pm 0.11^{\mathrm{axy}}$ \\
\hline GP-II & $8.15 \pm 0.11^{\mathrm{bx}}$ & $8.50 \pm 0.155^{\mathrm{bx}}$ & $10.30 \pm 0.12^{\mathrm{by}}$ & $9.45 \pm 0.28^{\mathrm{bz}}$ \\
\hline GP-III & $15.0 \pm 0.16^{\mathrm{cx}}$ & $14.50 \pm 0.14^{\mathrm{cxw}}$ & $16.1 \pm 0.23^{\mathrm{cy}}$ & $14.18 \pm 0.28^{\mathrm{azw}}$ \\
\hline GP-IV & $10.20 \pm 0.28^{\mathrm{dx}}$ & $11.51 \pm 0.12^{\mathrm{dy}}$ & $12.50 \pm 0.18^{\mathrm{dz}}$ & $13.48 \pm 0.15^{\mathrm{aw}}$ \\
\hline GP-V & $8.5 \pm 0.12^{\mathrm{bx}}$ & $8.90 \pm 0.23^{\mathrm{bx}}$ & $10.9 \pm 0.23^{\text {by }}$ & $10.56 \pm 0.43^{\mathrm{cy}}$ \\
\hline
\end{tabular}

Values with different superscripts in a row and column vary significantly at $\mathrm{p}<0.05$

Table.2 The mean $( \pm \mathrm{SE})$ values of total erythrocyte count (TEC) $\left(\times 10^{6} / \mathrm{mm}^{3}\right)$ of groups at different time intervals

\begin{tabular}{|l|l|l|l|l|}
\hline \multirow{2}{*}{ Groups } & \multicolumn{4}{|c|}{ Days of post treatment } \\
\cline { 2 - 5 } & $07^{\text {th }}$ & $14^{\text {th }}$ & $28^{\text {th }}$ & $45^{\text {th }}$ \\
\hline GP-I & $7.945 \pm 0.045^{\text {ax }}$ & $7.5 \pm 0.12^{\text {ax }}$ & $7.975 \pm 0.05^{\text {ax }}$ & $7.865 \pm 0.153^{\text {ax }}$ \\
\hline GP-II & $4.02 \pm 0.02^{\text {bx }}$ & $4.19 \pm 0.03^{\text {bxz }}$ & $5.17 \pm 0.22^{\text {by }}$ & $4.725 \pm 0.609^{\text {bxyz }}$ \\
\hline GP-III & $8.015 \pm 0.172^{\text {ax }}$ & $7.25 \pm 0.06^{\text {ayz }}$ & $7.95 \pm 0.06^{\text {axz }}$ & $7.44 \pm 0.18^{\text {acxz }}$ \\
\hline GP-IV & $5.04 \pm 0.01^{\text {cx }}$ & $5.67 \pm 0.02^{\text {cxy }}$ & $6.22 \pm 0.02^{\text {cyz }}$ & $6.915 \pm 0.157^{\mathrm{cz}}$ \\
\hline GP-V & $4.205 \pm 0.03^{\text {bx }}$ & $4.72 \pm 0.04^{\text {bxz }}$ & $5.475 \pm 0.182^{\text {by }}$ & $5.23 \pm 0.335^{\text {byz }}$ \\
\hline
\end{tabular}

Values with different superscripts in a row and column vary significantly at $\mathrm{p}<0.05$

Table.3 The mean $( \pm \mathrm{SE})$ values of total leukocyte count (TLC) $\left(10^{3} / \mathrm{mm}^{3}\right)$ of different groups at different time intervals

\begin{tabular}{|l|l|l|l|l|}
\hline \multirow{2}{*}{ Groups } & \multicolumn{4}{|c|}{ Days of post treatment } \\
\cline { 2 - 5 } & $07^{\text {th }}$ & $14^{\text {th }}$ & $28^{\text {th }}$ & $45^{\text {th }}$ \\
\hline GP-I & $7.73 \pm 0.02^{\mathrm{ax}}$ & $7.74 \pm 0.02^{\mathrm{axyz}}$ & $8.01 \pm 0.02^{\mathrm{ay}}$ & $7.56 \pm 0.17^{\mathrm{axz}}$ \\
\hline GP-II & $4.9 \pm 0.02^{\mathrm{bx}}$ & $5.37 \pm 0.01^{\mathrm{by}}$ & $5.79 \pm 0.03^{\mathrm{bz}}$ & $6.32 \pm 0.09^{\mathrm{bw}}$ \\
\hline GP-III & $7.63 \pm 0.11^{\mathrm{ax}}$ & $7.65 \pm 0.14^{\mathrm{ax}}$ & $8.03 \pm 0.01^{\mathrm{ay}}$ & $7.76 \pm 0.06^{\mathrm{acxy}}$ \\
\hline GP-IV & $7.135 \pm 0.01^{\mathrm{cx}}$ & $7.11 \pm 0.02^{\mathrm{cx}}$ & $7.38 \pm 0.02^{\mathrm{cx}}$ & $7.92 \pm 0.06^{\mathrm{cy}}$ \\
\hline GP-V & $6.18 \pm 0.04^{\mathrm{dx}}$ & $6.14 \pm 0.01^{\mathrm{dx}}$ & $6.28 \pm 0.08^{\mathrm{dxz}}$ & $6.53 \pm 0.09^{\mathrm{dyz}}$ \\
\hline
\end{tabular}

Values with different superscripts in a row and column vary significantly at $p<0.05$ 
Table.4 The mean $( \pm \mathrm{SE})$ values of platelets $\left(\mathrm{x} 10^{3} / \mathrm{mm}^{3}\right)$ of different groups at different time intervals

\begin{tabular}{|l|l|l|l|l|}
\hline \multirow{2}{*}{ Groups } & \multicolumn{3}{c|}{ Days of post treatment } \\
\cline { 2 - 5 } & $07^{\text {th }}$ & $14^{\text {th }}$ & $28^{\text {th }}$ & $45^{\text {th }}$ \\
\hline GP-I & $607.5 \pm 5.8^{\mathrm{ax}}$ & $577.5 \pm 1.93^{\mathrm{axy}}$ & $626.5 \pm 25.69^{\mathrm{axz}}$ & $640 \pm 26.6^{\mathrm{axz}}$ \\
\hline GP-II & $177.5 \pm 7.87^{\mathrm{bx}}$ & $331 \pm 7.74^{\mathrm{by}}$ & $365 \pm 8.26^{\mathrm{byz}}$ & $385.5 \pm 8.52^{\mathrm{bz}}$ \\
\hline GP-III & $681 \pm 24.52^{\mathrm{cx}}$ & $631 \pm 1.54^{\mathrm{cy}}$ & $694 \pm 20.91^{\mathrm{cx}}$ & $680.16 \pm 12.30^{\mathrm{ax}}$ \\
\hline GP-IV & $404.5 \pm 0.9^{\mathrm{dx}}$ & $456.5 \pm 1.67^{\mathrm{dy}}$ & $492.5 \pm 1.16^{\mathrm{dz}}$ & $507.83 \pm 5.37^{\mathrm{cz}}$ \\
\hline GP-V & $202.5 \pm 4.51^{\mathrm{bx}}$ & $345.5 \pm 6.58^{\mathrm{by}}$ & $377.0 \pm 8.5^{\mathrm{byz}}$ & $398.33 \pm 9.85^{\mathrm{bz}}$ \\
\hline
\end{tabular}

Values with different superscripts in a row and column vary significantly at $\mathrm{p}<0.05$

Fig.1 The mean $( \pm$ SE) values of hemoglobin $(\mathrm{g} \%)$ of different groups at different time intervals

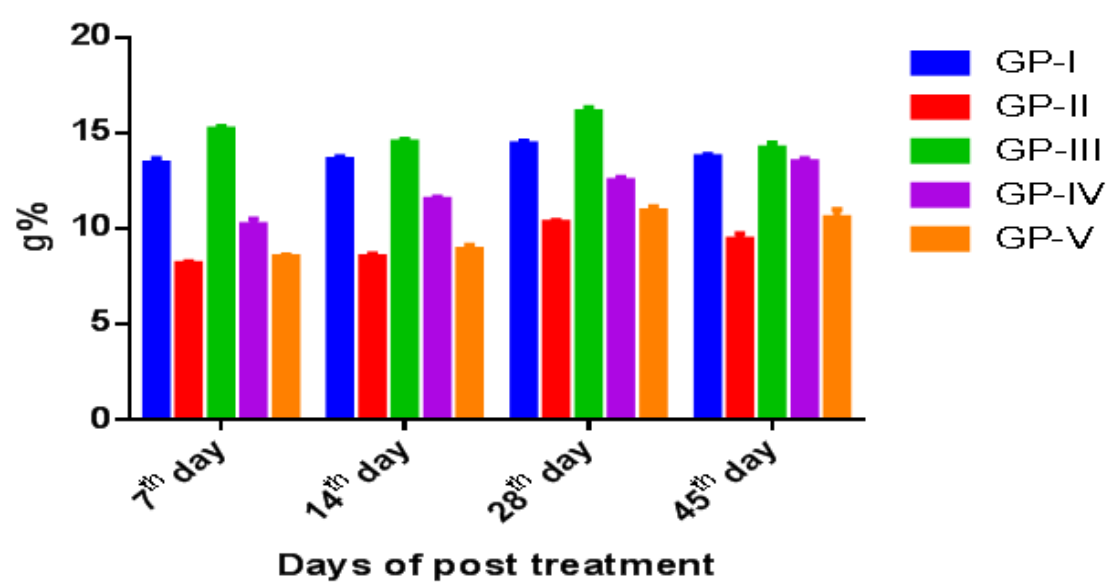

Fig.2 The mean $\left( \pm\right.$ SE) values of total erythrocyte count $\left(\right.$ TEC) $\left(\times 10^{6} / \mathrm{mm}^{3}\right)$ of different groups at different time intervals

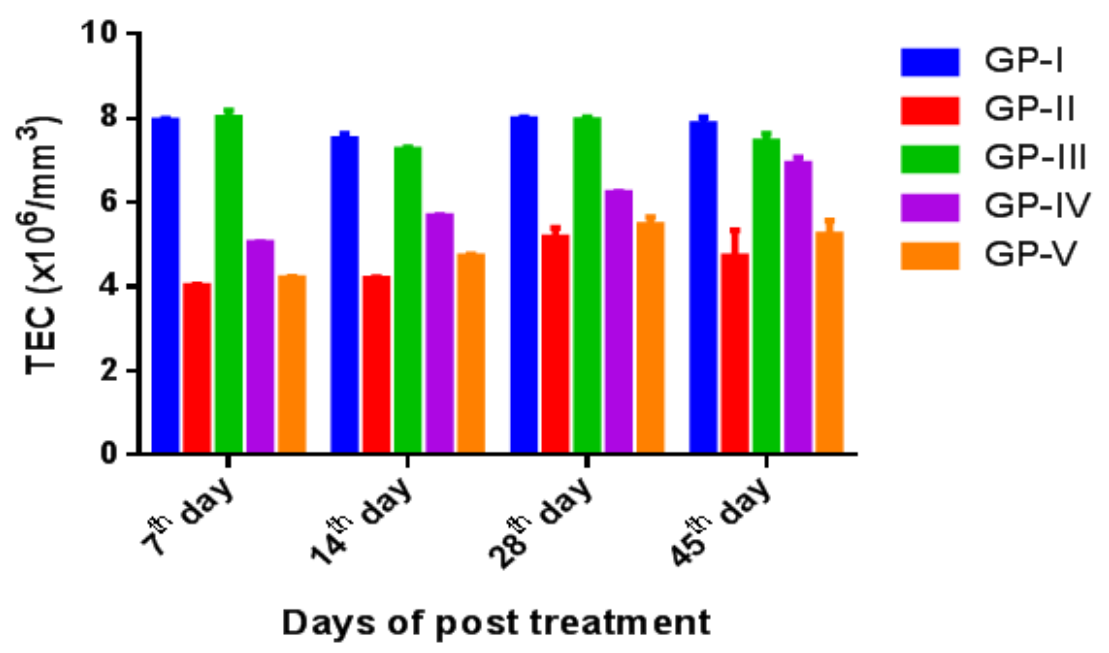


Fig.3 The mean $\left( \pm\right.$ SE) values of total leukocyte count (TLC) $\left(10^{3} / \mathrm{mm}^{3}\right)$ of different groups at different time intervals

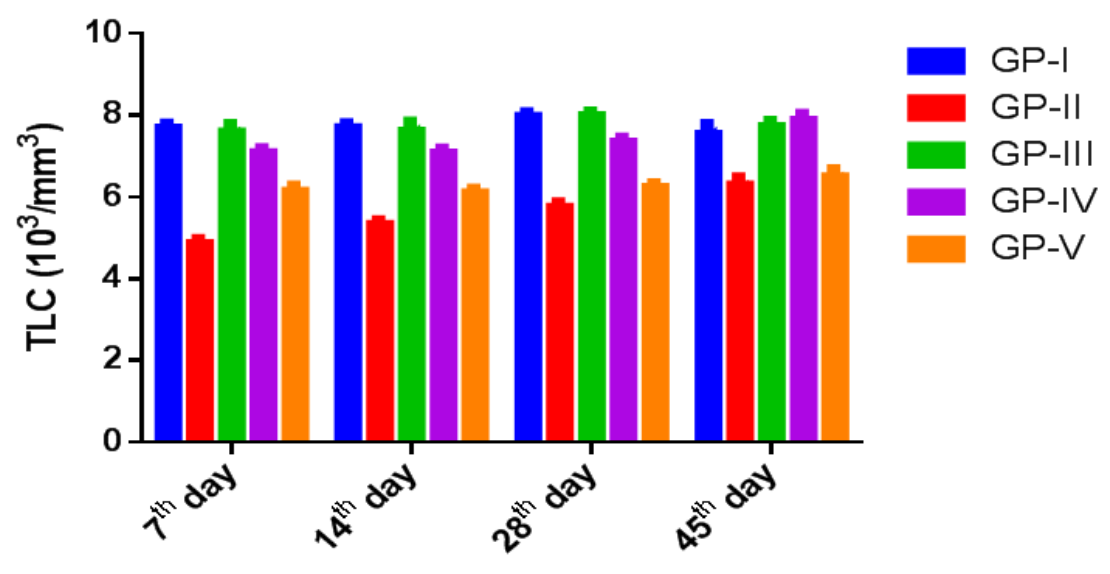

Days of post treatment

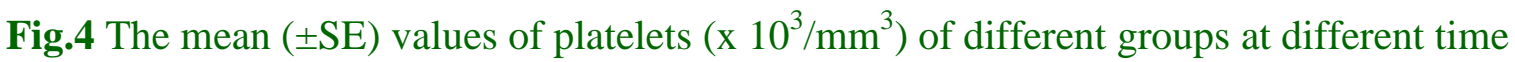
intervals

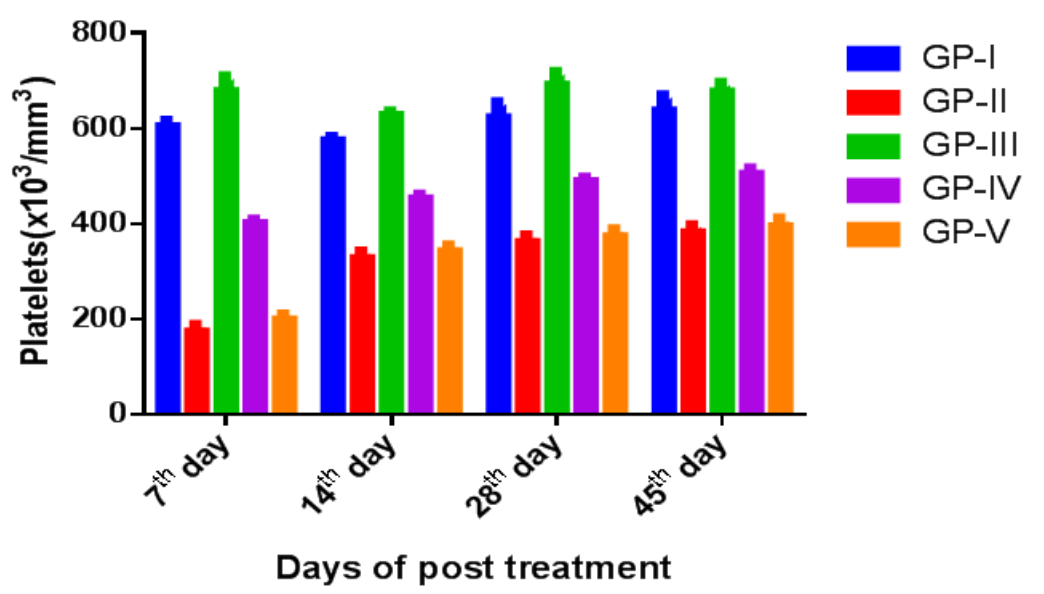

In the present study, pretreatment with ethanolic extract of AP ameliorated the deleterious effects of $\mathrm{CP}$ which was reflected by significant improvement $(P<0.05)$ in the levels of hemoglobin, TEC,TLC and platelet count in the animals of Group-IV on all the days of the observation compared to Group II animals (Table 1, 2, 3, 4 and Figure 1, 2, 3, 4). However, the concurrent AP group (Group $\mathrm{V})$ showed meagre non-significant increase in the values of hemoglobin, TEC, platelets count and significant $(P<0.05)$ increase in the levels of TLC on all the days of observation compared to Group II animals. In addition, when values were compared between the groups IV and V, the AP pretreatment group (Group IV) showed significant $(\mathrm{p}<0.05)$ improvement. These observations indicated that though AP has ameliorating effect on cisplatin induced hematological changes in general, the pretreatment of AP has preventive effects against cisplatin injury which prevented the alterations much prior to AP administration simultaneously with CP. 
Similar protective effects of AP and improvement of haemopoietic function has also been reported earlier in cyclophosphamide induced toxicity in mice (Sheeza and Kuttan, 2006) and experimental aflatoxicosis in broiler (Sapcota et al., 2006). The protective and ameliorating effects of the extract of the plant Andrographis paniculata could be attributed through various mechanisms such as free radical scavenging, inhibition of lipid peroxidation, increase in the bone marrow cellularity and immunomodulatory activity (Trivedi and Rawal, 2001 and Sheeza and Kuttan, 2006). Administration of the ethanolic extract of AP increase the weight of the lymphoid organs especially spleen and thymus in cyclophosphamide treated mice providing the supportive evidence of immunostimulatory potential (Sheeza and Kuttan, 2006). Andrographolide also stimulates the production of the cytotoxic lymphocytes and hence inhibit the tumor growth in animals (Sheeza and Kuttan, 2007).

In conclusion the study highlighted the beneficial effects of Andrographis paniculata at $500 \mathrm{mg} / \mathrm{kg}$ body weight in ameliorating the toxic effect on $\mathrm{CP}$ induced hematological changes in Wistaralbino rats and the possible preventive role of AP against $\mathrm{CP}$ induced toxicity.

\section{Acknowledgement}

Authors are the thankful to the Dean, Veterinary College, Bengaluru and Head of the Department for providing the necessary facilities.

\section{References}

Abdel Salam, G., Hegazy, A.M.S., Ali, A.M. and Rizk, A.H. 2012. Silymarin ameliorates hepatotoxic effect of Cisplatin: A structural and ultrastructural study of adult albino rats. J. Am. Sci., 8: 490-498.
Akbar, S. 2011. Andrographis paniculata: a review of pharmacological activities and clinical effects, Altern Med Rev.,16(1): 6677.

Bardi, D. A, Halabi, M. F, Hassandarvish, P., Rouhollahi, E. and Paydar, M. 2014. Andrographis paniculata Leaf Extract Prevents Thioacetamide-Induced Liver Cirrhosis in Rats. PLoS ONE., 9(10): e109424. doi: 10.1371/journal.pone.0109424.

Basu, A., Ghosh, P., Bhattacharjee, A., Patra, A.R and Bhattacharya, S. 2015. Prevention of myelosuppression and genotoxicity induced by cisplatin in murine bone marrow cells: effect of an organovanadium compound vanadium (III)-L-cysteine. Mutagenesis, 30(4): 509-517.

Bhachandra, W., Alqadhi, Y.A. and Ninawe, A., 2018. Ameliorative role of bee honey and royal jelly against cisplatin induced Alteration In Hematological parameters in Male Wistar albino Rat. Int $J$ Pharm Pharmaceut Sci, 10(4): 10.

Divya, M.K., Lincy, L., Raghavamenon, A.C. and Babu, T.D., 2016. Ameliorative effect of Apodytesdimidiataon cisplatin-induced nephrotoxicity in Wistar rats. Pharm. Biol., 54(10): 2149-2157.

Hassan, I., Chibber, S., Naseem, I. 2010. Ameliorative effect of riboflavin on the cisplatin induced nephrotoxicity and hepatotoxicity. Food Chem. Toxicol., 48 (89): 2052-2058.

Hemati, S., N.A. Jolfaie, A. Gookizadeh and Rafienia, M. 2012. The effects of vitamin E and selenium on cisplatin-induced nephrotoxicity in cancer patients treated with cisplatin-based chemotherapy: A randomized, placebo-controlled study. $J$. Res. Med. Sci., 17: 49-58.

Iseri, S. Ercan, F., Gedik, N., Yuksel, M. Alican, I. 2007. Simvastatin attenuates cisplatininduced kidney and liver damage in rats, Toxicol., 230(2-3): 256-264.

Karale, S. and Kamath, J.V., 2017. Effect of daidzein on cisplatin-induced hematotoxicity and hepatotoxicity in experimental rats. Indian J. Pharmacol., 49(1): 49-54.

Lijuv, B., Jeena, K., Kuttan, R. 2013. Acute and 
subchronic toxicity as well asmutagenic evaluation of essential oil from turmeric Curcuma longaL., Food Chem. Toxicol., 3: 52-61.

Lin, M.T., Ko, J.L., Liu, T.C., Chao, P.T. and Ou, C.C. 2018. Protective effect of d-methionine on body weight loss, anorexia, and nephrotoxicity in cisplatin-induced chronic toxicity in rats. Integr.cancerTher., 17(3): 813-824.

Markovic, S.D. Zizic, J.B., Djacic, D.S. Obradovic, A.D. Curcic, M.G. Cvetkovic, D.M. Đordevic, N.Z. Ognjanovic, B.A. 'Stajn, A.S. 2011. Alteration of oxidative stress parameters in red blood cells of rats after chronic in vivo treatment with cisplatin and selenium, Arch. Biol. Sci., 63 (4): 991999.

Nasr, A.Y. 2014. Protective effect of aged garlic extracts against the oxidative stress induced by cisplatin on blood cells parameters and hepatic antioxidant enzymes in rats. Toxicology reports., 1: 682-691.

Nowis, D., Legat, M., Bil, J., Kurzaj, Z., Issat, T., Stoklosa, T., Mioduszewska, B., Kaczmarek, L., Jakobisiak, M and Golab, J. 2007. Erythropietin reduces cisplatin induced neurotoxicity without impairment of cytotoxic effects against tumor cells. Int. J. Oncol., 31: 1547-1552.

Olas, B. Wachowicz, B. Majsterek, I. Blasiak, J. 2005. Resveratrol mayreduce oxidative stress induced by platinum compounds in humanplasma, blood platelets and lymphocytes. Anticancer Drugs., 16: 659665.

Ramya, B., Anjaneyulu, Y. and Reddy, A.G., 2013. A study on cisplatin-induced toxic effects in rats with respect to hematology, performance, relative organ weights $(\%)$ and gastrointestinal toxicity. Int. J. Rec Sci Res., 4 (09): 1304- 1307.
Sapcota, D., Islam, T.N. and Upadhyaya, R., 2006. Experimental aflatoxicosis in commercial broilers and its amelioration by dietary Andrographis paniculata: A haemato-pathological study. Ani. Nutr. Feed Technol., 6(2): 177-184.

Shalaby, R.H., Rashed, L.A., Ismail, A.E., Madkour, N.K. and Elwakeel, S.H. 2014. Genetic and histological studies on effect of mesenchymal stem cell therapy on experimental renal injury induced by cisplatin in male albino rats. World $J$. Pharm. Sci., 3: 131-156.

Shaymaa, I. S., Abeer, A., Abdel-Baky and Faten F., M. 2017. Cytoprotective Effect of Silymarin on Cisplatin Induced Hepatotoxicity and Bone Marrow Toxicity in Rats. Asian J. Animal Sci., 11: 140-152.

Sheeja K and Kuttan G. 2007. Activation of cytotoxic $\mathrm{T}$ lymphocyte responses and attenuation of tumor growth in vivo by Andrographis paniculata extract and andrographolide. Immunopharmacol Immunotoxicol., 29(1): 81-93.

Sheeja, K. and Kuttan, G., 2006. Ameliorating effects of Andrographis paniculata extract against cyclophosphamide-induced toxicity in mice. Asian Pacific. J. Cancer Prev., 7(4): 609-614.

Song, Z., Chang, H., Han, N., Liu, Z., Liu, Y., Wang, H., Shao, J., Wang, Z., Gao, H. and Yin, J., 2017. He-Wei granules (HWKL) combat cisplatin-induced nephrotoxicity and myelosuppression in rats by inhibiting oxidative stress, inflammatory cytokines and apoptosis. $R S C A d v$., 7(32): 19794-19807.

Trivedi N, P. and Rawal, U. M. 2001. Hepatoprotective and antioxidant property of Andrographis paniculata (Nees) in BHC induced liver damage in mice. Indian J. Exp. Biol., 39: 4 1-46.

\section{How to cite this article:}

Rajendrakumar, T., Suguna Rao, M. L. Satyanarayana, H. D. Narayanaswamy, S. M. Byregowda and Shridhar, N. B. 2020. Hematological Alterations in Cisplatin Induced Toxicity in Rats and Its Amelioration by Andrographis paniculata. Int.J.Curr.Microbiol.App.Sci. 9(04): 525-532. doi: https://doi.org/10.20546/ijcmas.2020.904.063 